\title{
0 IDOSO NA UNIVERSIDADE: INCLUSÃO, EDUCAÇÃO E EXTENSÃO UNIVERSITÁRIA
}

\author{
ELDERLY IN UNIVERSITY: INCLUSION, EDUCATION AND UNIVERSITY \\ EXTENSION
}

\section{EL ADULTO MAYOR EN LA UNIVERSIDAD: INCLUSIÓN, EDUCACIÓN Y EXTENSIÓN UNIVERSITARIA}

\author{
Rita de Cássia da Silva Oliveira* \\ Paola Andressa Scortegagna* \\ Flávia Oliveira Alves da Silva***
}

\begin{abstract}
Resumo: O envelhecimento da população mundial se apresenta como um fenômeno real, comprovado pelo censo que registra atualmente uma população de 25 milhões de idosos na sociedade brasileira. Ressalta-se que a educação se configura como uma importante ferramenta para a conscientização dos sujeitos e possibilita maior inclusão e participação social. O idoso sofre um processo de exclusão social, que aos poucos tenta ser superado pela implantação de políticas públicas que garantam direitos básicos a esta faixa etária, em especial aqui enfatizado o direito à educação, conforme prescrito no Estatuto do Idoso. Para a garantia deste direito, a sociedade deve se basear em uma concepção de inclusão não apenas como um movimento educacional, mas como um processo social e político. A educação inclusiva não é aquela que apenas aceita as diferenças, mas faz da diferença uma maneira distinta de expressão e de operacionalização do mundo. A universidade, no desempenho de suas funções (ensino, pesquisa e extensão),em especial, a extensão, oferece projetos para a educação do idoso, podendo-se citar a Universidade Aberta para a Terceira Idade. Este artigo objetiva refletir sobre a função extensionista da universidade e as Universidades Abertas para a Terceira Idade como ação para a inclusão e o empoderamento do idoso. O estudo também estabelece um perfil dos idosos que frequentam diferentes UATI brasileiras. Foi realizada uma pesquisa bibliográfica e de campo, com a aplicação de questionários para idosos de 12 UATI de diferentes regiões geográficas. Pode-se identificar a heterogeneidade dos alunos das UATI investigadas.
\end{abstract}

Palavras-chave: Idoso. Terceira idade. Inclusão social. Universidade Aberta para a Terceira Idade. Extensão.

\begin{abstract}
The aging of the world population is presented as a real phenomenon, evidenced by the census which currently records a population of 25 million elderly in Brazilian society. It is emphasized that education is configured as an important tool in the process of awareness of the subject and allows for greater inclusion and social participation. The elderly suffer a process of social exclusion, which gradually tries to be overcome by the implementation of public policies that guarantee basic rights to this age group, especially here emphasized the right to education as prescribed in the status of the elderly. To guarantee this right, the society must be based on a conception of inclusion not only as an

\footnotetext{
*Universidade Estadual de Ponta Grossa - UEPG. E-mail: soliveira13@uol.com.br

${ }^{* *}$ Universidade Estadual de Ponta Grossa - UEPG. E-mail: paola_scortegagna@hotmail.com

${ }^{* * *}$ Universidade Católica de Argentina. Universidade do Norte Paranaense. E-mail: flasoliveira@uol.com.br
} 
educational movement, but as a social and political process. Inclusive education is not the one that just accepts the differences, but make from difference a different way of expression and operation of the world. The university, in performing their functions (teaching, research and extension), in particular, the extension offers projects for the education of the elderly, it can be mentioned the Open University for the Third Age. This article aims to reflect on the extension function of the university and the Open University for the Third Age as action for the inclusion and empowerment of the elderly. The study also provides a profile of the elderly who attend different Brazilian UATI. A literature and field research was conducted with the use of questionnaires to 12 UATI elderly from different geographical regions. It Can be identified the heterogeneity of the students investigated UATI.

Keywords: Elderly. Third age. Social inclusion. Open University for the Third Age. Extension.

Resumen: El envejecimiento de la población mundial se presenta como un fenómeno real, evidenciado por el censo que registra actualmente una población de 25 millones de personas mayores en la sociedad brasileña. Se resalta que la educación se configura como una herramienta importante en el proceso de la conciencia del sujeto y permite una mayor inclusión y participación social. Las personas mayores sufren un proceso de exclusión social, que intenta poco a poco ser superado por la implementación de políticas públicas que garanticen los derechos básicos de este grupo de edad, sobre todo aquí enfatizado en el derecho a la educación como prescrito en el Estatuto del Anciano. Para garantizar este derecho, la sociedad debe basarse en una concepción de la inclusión no sólo como un movimiento educativo, sino como un proceso social y político. La educación inclusiva no es la que sólo acepta las diferencias, pero la diferencia es una forma diferente de expresión y el funcionamiento del mundo. La universidad, en el desempeño de sus funciones (enseñanza, investigación y extensión), en particular, la extensión, ofrece proyectos para la educación de las personas mayores, y se puede citar la Universidad Abierta de la Tercera Edad. Este artículo tiene como objetivo reflexionar la función de extensión de la universidad y las Universidades Abiertas para la Tercera Edad como acción para la inclusión y la autonomía de las personas mayores. El estudio también establece un perfil de los ancianos que asisten a diferentes UATI brasileñas. Fue realizada una pesquisa bibliográfica y de campo, con la aplicación de cuestionarios de 12 UATI de diferentes regiones geográficas. Se pudo identificar la heterogeneidad de los alumnos de las UATI investigadas.

Palabras claves: Persona mayor. Tercera edad. Inclusión social. Universidad Abierta para la Tercera Edad. Extensión.

\section{Introdução}

A educação se configura como uma importante ferramenta para o processo de conscientização dos sujeitos, tornando-os conhecedores dos seus direitos e deveres, além de impulsionar a possibilidade de participação social e da atuação em diferentes campos.

Os processos educativos acontecem nos mais diferentes espaços formais, não formais e informais. Cada instituição de caráter educacional deve exercer suas funções, considerando as particularidades e demandas do segmento a que atende.
As universidades possuem grande parcela de responsabilidade diante da tarefa de educar. Embora cada uma destas entidades possua sua especificidade, não exclui a existência de diretrizes gerais, incluindo aquelas expressas em leis, que permeiam as ações universitárias, restritas ao próprio contexto histórico social.

O pluralismo social e cultural da vida moderna faz com que as funções da universidade se ampliem. Conforme afirma Saviani (1990, p. 26), de acordo com a reforma universitária, “[...] três são as atividades fins 
da Universidade: o ensino, a pesquisa e a extensão".

Existe uma convergência e consciência progressiva por parte das instituições universitárias, em sua totalidade, no sentido de que a massa crítica de recursos acumulados na universidade deve ser necessariamente estendida ao maior número de pessoas possível, processo esse denominado de extensão universitária. Assim, a terceira função da universidade, não menos importante, é a extensão, ou seja, a articulação da universidade com a sociedade.

O idoso na sociedade brasileira ainda é alvo de inúmeras discriminações em diferentes aspectos, como familiar, econômico, no mercado de trabalho, social, entre outros. Este paradigma preconceituoso da velhice que foi solidificado e cultivado na sociedade brasileira lentamente é desconstruído pelas políticas públicas, pelos idosos e pela sociedade como um todo, sendo substituído pelo Paradigma do Envelhecimento Ativo. A educação assume papel preponderante na disseminação desta nova visão da velhice, pela inclusão social do idoso. O conhecimento é um instrumento eficiente e necessário para o empoderamento, em especial, para os idosos, na tentativa de superar os desequilíbrios sociais.

Este artigo objetiva refletir sobre a função extensionista da universidade e as Universidades Abertas para a Terceira Idade como ação para a inclusão e o empoderamento do idoso. $\mathrm{O}$ estudo também estabelece um perfil dos idosos que frequentam diferentes UATIs brasileiras. Foi realizada uma pesquisa bibliográfica e de campo, com a aplicação de questionários para idosos de 12 UATIs brasileiras de diferentes regiões geográficas.

\section{Extensão universitária}

A extensão é uma via de mão dupla, na qual a universidade, por meio de sua responsabilidade social, cumpre seu papel extensionista, levando à comunidade os produtos do ensino e pesquisa. Já a comunidade, em contrapartida, devolve à universidade suas experiências, conhecimentos e cultura, num constante diálogo entre o contexto universitário e comunitário.

Toda ação extensionista deve ser considerada num movimento horizontal, articulado ao ensino e à pesquisa, resultando num processo qualitativo de ações que objetivam contribuir significativamente para o desenvolvimento da comunidade, nos mais diversos âmbitos. Logo, a extensão é práxis e promove a relação entre os conhecimentos acadêmicos e populares, na interlocução entre universidade e comunidade.

As ações extensionistas emergem a partir de questões sociais, havendo a necessidade de buscar alternativas para a transformação da realidade de diferentes sujeitos. Para que isso seja possível, cabe a aproximação da academia com a comunidade, a fim de promover a relação entre o saber teórico e científico com o saber popular e a cultura, tendo como finalidade melhorar a qualidade de vida das pessoas, no sentido amplo.

É necessário reconhecer a cultura e o saber popular, com os quais é preciso dialogar, a fim de traçar uma trajetória para a transformação social que promova uma relação direta com o que se ensina e se pesquisa. Neste sentido, Serrano (s/d) destaca que há necessidade de mudanças na forma de atuação das universidades em sua relação com a sociedade, pois a extensão é um processo educativo, cultural e científico.

Corroborando com esta questão, Guimarães, Ferreira e Villaça (2008, p. 73) afirmam que "[...] a ação da extensão pretende: conscientizar a comunidade de sua participação nas questões comunitárias que precisam ser discutidas por todos os engajados neste 
processo de desenvolvimento da sociedade”. Além disso, é indispensável "[...] reunir esforços voltados para a difusão dos conhecimentos necessários ao aprimoramento das estratégias de inclusão social dos segmentos mais vulneráveis da sociedade”.

A partir da organização do Fórum Nacional de Pró-Reitores de Extensão das Universidades Públicas Brasileiras (FORPROEX), em 1987, a preocupação e as discussões acerca da extensão universitária começam a ganhar destaque. O FORPROEX, desde sua fundação, realiza fóruns com o objetivo de desenvolvimento do campo. Há inúmeras publicações que colaboram com o desenvolvimento extensionista, além da Política Nacional de Extensão, publicada em 1999.

Com a criação deste fórum, a preocupação com o desenvolvimento das atividades de extensão nas universidades ganhou reconhecimento, inclusive no que diz respeito à legislação. Na Constituição Federal (1988), no artigo 207, a atividade da extensão é considerada, em consonância com o ensino e a pesquisa, uma tríade indissociável (“[...] as universidades gozam de autonomia didático-científica, administrativa e de gestão financeira e patrimonial, e obedecerão ao princípio de indissociabilidade entre ensino, pesquisa e extensão.”).

Na Lei de Diretrizes e Bases da Educação Nacional (LDB 9394/96), no que diz respeito às atividades universitárias, considera-se, no artigo 43 (finalidade da educação superior), inciso VII: “[...] promover a extensão, aberta à participação da população, visando à difusão das conquistas e benefícios resultantes da criação cultural e da pesquisa científica e tecnológica geradas na instituição”.

Nogueira (2001) ressalta a importância do FORPROEX para o desenvolvimento da extensão e a relação direta entre os pressupostos legais, considerados na legislação vigente. Segundo a autora, a criação do Fórum Nacional teve como base algumas questões já consensuais entre seus membros participantes, as quais seriam o fundamento para elaboração das políticas de Extensão.

Isso significa que o entendimento entre os Pró-Reitores se deu a partir dessas ideias, que podem ser apreendidas como conclusões dos documentos dos encontros regionais. São elas: o compromisso social da Universidade na busca da solução dos problemas mais urgentes da maioria da população; a indissociabilidade entre as atividades de Ensino, Extensão e Pesquisa; o caráter interdisciplinar da ação extensionista; a necessidade de institucionalização da Extensão no nível das instituições e no nível do MEC; o reconhecimento do saber popular e a consideração da importância da troca entre este e o saber acadêmico; e a necessidade de financiamento da Extensão como responsabilidade governamental. (NOGUEIRA, 2001).

Para que haja o desenvolvimento da atividade nas universidades, é necessário um longo processo, conforme aponta Nogueira (2001). O FORPROEX traz significativas contribuições neste sentido, pois, a partir da sua ação, foi possível a elaboração da Política Nacional da Extensão e do Plano Nacional da Extensão Universitária. Esta política está pautada nas questões sociais, fundamentada pelas relações dialógicas (FREIRE, 2008) e nos princípios do empoderamento.

A extensão universitária, além de determinação legal, deve avançar no que diz respeito às ações comunitárias, contribuindo para que o conhecimento e a pesquisa universitária encontrem finalidade e que não se findem no espaço acadêmico. Esta atividade tem por excelência a aproximação da comunidade à universidade. 
No que diz respeito à função extensionista, cabe salientar que tal atividade não tem como objetivo sanar as deficiências das funções do Estado em relação à comunidade, mas, sim, contribuir para o desenvolvimento cultural, social, educacional, científico e tecnológico.

Conforme aponta o FORPROEX (2007, p. 34), a extensão não é uma atividade com fim em si própria, mas revela seu compromisso social, não substituindo o Estado, porém como um grande laboratório de criação, de materialização de práticas que podem contribuir para a consolidação de políticas públicas.

Neste sentido, a atuação da extensão ocorre em grandes áreas temáticas, organizadas a partir da Política Nacional de Extensão: Comunicação, Cultura, Direitos Humanos e Justiça, Educação, Meio Ambiente, Saúde, Tecnologia e Produção e Trabalho.

Assim, Castro (2004, p. 14) afirma que a extensão “[...] se coloca como um espaço estratégico para promover práticas integradas entre as várias áreas do conhecimento.” Além disso, a mesma autora aponta que, para que este processo possa ocorrer,

[...] é necessário criar mecanismos que favoreçam a aproximação de diferentes sujeitos, favorecendo a multidisciplinaridade; potencializa, através do contato de vários indivíduos, o desenvolvimento de uma consciência cidadã e humana, e assim a formação de sujeitos de mudança, capazes de se colocar no mundo com uma postura mais ativa e crítica. A extensão trabalha no sentido de transformação social. (CASTRO, 2004, p. 14).

Reconhecer a atividade extensionista e entender suas funções é indispensável para o desenvolvimento do ensino superior no Brasil. Este avanço permite diminuir a distância entre os conhecimentos acadêmicos e os de senso comum, não pormenorizando um em detrimento do outro, ao contrário, valorizando um para a evolução e desenvolvimento do outro.

A partir deste fundamento, as ações desenvolvidas na universidade devem avançar e possibilitar o desenvolvimento humano e social.

Diante da atuação extensionista da universidade, tendo como fundamento os conceitos freireanos, destacam-se os mais diferentes programas e projetos que atendem inúmeras demandas sociais, dentre as quais há maior incidência de atuação junto aos grupos mais vulneráveis.

Um dos grupos que tem tido uma maior amplitude de atenção e atendimento em relação aos programas e projetos extensionistas é o dos idosos. Em relação às ações para a terceira idade nas instituições de ensino superior (IES), há uma expressiva quantidade de programas/projetos para a educação deste grupo etário.

Estes programas/projetos para a educação do idoso nas IES pautam-se na educação permanente e não formal, possibilitando a inclusão social e o empoderamento da terceira idade.

\section{Inclusão social}

Considerando o processo de inclusão social, não basta apenas pautar-se num processo de educação inclusiva, mas é necessário que esteja fundamentado a partir da concepção de uma sociedade inclusiva. $\mathrm{O}$ processo inclusivo está pautado no respeito, na aceitação das diferenças e na ampla colaboração entre os indivíduos. (FREIRE, 2008).

Desta forma, é fundamental entender que a inclusão, além de um movimento educacional, é também um processo social 
e político, que visa defender o direito de todos à participação, de maneira responsável e consciente. Há necessidade de trabalhar para que haja a aceitação e o respeito diante das características que diferenciam os indivíduos de determinado grupo em relação à sociedade. (FREIRE, 2008).

Sobre a inclusão social, Torres e Sá (2008, p. 5) afirmam que este processo “[...] corre paralelo à discussão do direito e da proteção social.” Os mesmos autores apontam que, na sociedade atual, os direitos sociais são geralmente identificados como favor ou benefício e não como prerrogativa para uma vida digna e de qualidade.

Apesar de haver diversas políticas públicas que garantam os direitos elementares para efetivação da inclusão social dos indivíduos, muitas vezes a efetivação destas políticas não ocorre e seus direcionamentos por vezes são obscuros e não cumprem os objetivos estabelecidos, mantendo os processos de exclusão social.

Desta forma, “[...] a inclusão e a exclusão se referem às dinâmicas de expulsão ou de inserção nas esferas socialmente reconhecidas.” (FALEIROS, 2006, p. 2).

A exclusão social representa o processo de marginalização dos indivíduos, uma vez que estes se encontram imersos na condição de vulnerabilidade. De acordo com Faleiros (2006, p. 3):

A exclusão é um impedimento, uma barreira, uma fronteira elaborada socialmente em relações de poder, que dividem os grupos, de forma a estabelecer hiatos tanto nas condições objetivas de vida ou de meios de vida como na percepção de si mesmo como sujeito historicamente situado, numa sociedade e num determinado Estado em se que pactuam direitos e se compactuam com exclusões.
Deste modo, surge a demanda de uma dupla política social que enfrente os processos excludentes. Uma, que seja de caráter preventivo, com a reformulação de políticas econômicas e sociais, ampliando a oferta de trabalho, além de garantir as redes de proteção social aos precarizados. A outra seria de caráter reparador, propondo reduzir a zona de desfiliação. (CASTEL, 1998).

Para evitar a exclusão social, é necessário promover programas de intervenção, os quais devem objetivar a inclusão social dos excluídos, promovendo a cidadania e a participação destes grupos em situação de vulnerabilidade.

Assim, para que um indivíduo seja considerado cidadão, ele deve ter assegurado pelo Estado e pela sociedade condições para uma vida digna, sendo-lhe garantido, por meio de políticas públicas e ações efetivas “[...] viver e conviver com liberdade, igualdade, justiça e equidade democraticamente estabelecidas.” (FALEIROS, 2007, p. 49).

Sobre o processo de inclusão, com destaque aos idosos, a legislação própria preconiza a garantia de direitos elementares, para superar a exclusão social e a marginalização deste segmento etário.

De acordo com o Artigo $2^{\circ}$ do Estatuto do Idoso (Lei 10.741/03):

O idoso goza de todos os direitos fundamentais inerentes à pessoa humana, sem prejuízo de proteção integral de que trata esta Lei, assegurando-se-lhe, por lei ou por outros meios, todas as oportunidades e facilidades, para preservação de sua saúde física e mental e seu aperfeiçoamento moral, intelectual, espiritual e social, em condições de liberdade e dignidade.

Ainda sobre a inclusão da terceira idade na sociedade, o Estatuto do Idoso (Lei 10.741/03) garante o direito à vida (Artigos 
$8^{\circ}$ e $9^{\circ}$ ), à liberdade, ao respeito e à dignidade (Artigo 10), à saúde (Artigo 15), à educação, cultura, esporte e lazer (Artigos 20 a 25), ao trabalho (Artigos 26 a 28), à proteção (Artigo 43), à justiça (Artigos 69 a 71).

Diante das garantias legais para que o idoso possa fazer parte da sociedade, Faleiros (2007) explica que se presencia um processo de transição do aparo legal para o processo de reconhecimento dos direitos do idoso, considerado um sujeito de direitos que tem garantido o atendimento às suas necessidades, à dignidade, à velhice, à proteção e ao seu protagonismo no contexto social em que se está inserido.

Uma política pública para o idoso, tendo a educação como base, deve buscar uma proximidade com as questões da assistência social, mas também do direito, da saúde, da alimentação, da moradia, da previdência, num desenho intersetorial que permita que todos os direitos sejam contemplados e respeitados.

Assim, o apoio e amparo ao idoso são compromissos sociais, que devem articular todas as ações voltadas para este segmento, a fim de contribuir para a constituição de novos papéis sociais na velhice. Deve-se possibilitar que o idoso, como sujeito ativo, lute pelos seus direitos e tenha asseguradas condições mínimas de sobrevivência e cidadania.

Para que o idoso possa ser atuante nos espaços em que vive, há necessidade de um processo educacional inclusivo, o qual integre estes sujeitos e os aproximem aos demais grupos sociais, atuando para a superação das discriminações e preconceitos que envolvem a velhice.

Para Freire (2008, p. 13) “[...] a criação de uma educação inclusiva é entendida como um meio por excelência de difusão dos valores de justiça e equidade social, solidariedade, respeito e participação democrática”.
A prática da educação inclusiva surge como possibilidade de luta direta em relação à exclusão social que envolve os grupos minoritários, neste caso, a situação em que estão inseridos os idosos. A educação emerge como lócus da problematização dos direitos sociais dos sujeitos e dos processos de exclusão e inclusão, entendendo que, para que ocorra uma mudança cultural e social, é urgente uma atuação educacional que objetive o conhecimento e entendimento das políticas públicas e a inserção dos sujeitos no campo da luta pela defesa dos direitos para todos.

Neste sentido,

[...] a educação inclusiva tem importância fundamental, pois busca, por princípio básico, a minimização de todo e qualquer tipo de exclusão em arenas educacionais, e com isso, elevar ao máximo o nível de participação, coletiva e individual, de seus integrantes. (SANTOS; PAULINO, 2008, p. 12).

Ao se pensar na educação, deve-se situar a importância da cidadania, mas não apenas destinada a uma classe dominante, mas sim que seja possível para as minorias, para que estas encontrem na educação a possibilidade de ascensão e crescimento. Assim, “a democratização da cultura pode romper com o círculo de exclusão social” (LUTZ; TEIXEIRA, 2004, p. 149), permitindo que oportunidades sejam dadas àqueles que nunca as tiveram.

A educação inclusiva não é aquela que aceita as diferenças, mas faz da diferença uma maneira distinta de expressão e de operacionalização do mundo. Não basta reconhecer e aceitar a diferença. Há que se transformar a ação e a experiência variadas em algo que amplie a nossa visão de mundo no sentido de uma atitude cidadã em respeito às diferenças. Negar a diferença é submeter-se a padrões preestabelecidos, o que acarreta a perda da identidade. A perda da identidade, por sua vez, amputa-nos a 
condição de ser sujeito, nos colocando na de sujeitado. É contra isso que temos que lutar nos espaços com os quais nos relacionamos. (ALVES, 2008, p. 105).

A educação voltada para a terceira idade deve possibilitar a inserção social, o reconhecimento dos novos papéis sociais que os idosos assumem com o passar dos anos, além de permitir uma reflexão sobre como a sociedade estruturada em classes sociais é organizada. Com esse conhecimento, é preciso refletir sobre os meios possíveis para que a população, em especial os idosos, das classes menos abastadas, tenham condições de sobrevivência e garantias de melhor qualidade de vida, dignidade e cidadania.

Dentro dessa perspectiva de educação permanente aliada à consciência do papel extensionista das universidades e da importância do papel da instituição como agente facilitador do desenvolvimento de uma educação permanente articulando-se continuamente com a sociedade, buscou-se a difusão de conhecimentos e conversão dos conteúdos em uma força viva capaz de elevar o nível cultural geral da sociedade.

Diante da demanda demográfica brasileira com o envelhecimento real e cumprindo a legislação brasileira, em especial com o Estatuto do Idoso, reforçada pelas funções que são atribuídas às universidades (ensino, pesquisa e extensão), são oferecidas, pelas Instituições de Ensino Superior, ações extensionistas como formas alternativas de atendimento ao idoso e também aos indivíduos que vão envelhecer, visando, além de uma valorização, a uma maior conscientização da sociedade em geral a respeito do processo de envelhecimento da população no país.

Geralmente estas ações privilegiam a educação não formal, caracterizando-se pelo encontro de gerações, pela não obrigatoriedade de frequência, a ocorrência de ações e experiências em espaços e tempos mais flexíveis, não restritos aos fixados por órgãos reguladores etc. (COSTA, 2006).

Segundo Gohn (2006), a educação não formal representa várias dimensões, como a aprendizagem dos direitos numa perspectiva política, desenvolvimento de potencialidades, exercício de práticas comunitárias e sociais, aprendizagem que capacite para uma leitura de mundo, transmissão de informações, como também a formação política, social e cultural. A educação não formal acontece em compartilhamento de experiências, em espaços e ações coletivas e cotidianas.

Fundamentadas na educação não formal e na educação permanente, exercendo a função extensionista que compete às universidades, são criadas diferentes intervenções como programas, projetos e cursos voltados para o idoso, na busca de maior valorização, propiciar aquisição de conhecimentos, atualização, inserção e participação social do idoso.

\section{Metodologia e apresentação de dados}

Foi realizada uma pesquisa bibliográfica e pesquisa de campo em 12 Universidades Abertas para a Terceira Idade de diferentes universidades situadas nas regiões brasileiras. 
Quadro1: Instituições Pesquisadas

\begin{tabular}{l|l}
\hline Instituições & Regiões \\
\hline Universidade Estadual de Ponta Grossa - PR & Região Sul \\
\hline Universidade de Caxias do Sul - RS & Região Sul \\
\hline Universidade Regional de Blumenau - SC & Região Sul \\
\hline Universidade Federal do Espírito Santo - ES & Região Sudeste \\
\hline Universidade Federal de Alfenas- MG & Região Sudeste \\
\hline Universidade Estadual do Rio de Janeiro - RJ & Região Sudeste \\
\hline Universidade Católica Dom Bosco - MS & Região Centro Oeste \\
\hline Pontifícia Universidade de Goiás- GO & Região Centro Oeste \\
\hline Universidade Federal de Pernambuco- PE & Região Nordeste \\
\hline Universidade Estadual de Santa Cruz - BA & Região Nordeste \\
\hline Universidade Federal de Sergipe- SE & Região Nordeste \\
\hline Universidade do Estado do Amazonas - AM & Região Norte \\
\hline
\end{tabular}

Fonte: Elaboração das autoras com base nos dados coletados.

Nas instituições investigadas, como instrumento de coleta de dados foi utilizado um questionário com perguntas abertas e fechadas no intuito de identificar o perfil dos idosos que frequentam diferentes UATIs do país. Em cada instituição foram aplicados 15 questionários, com exceção da Universidade Estadual de Santa Cruz (BA) em que participaram 12 idosos. Ao todo são 177 questionários tabulados neste artigo.

Referente à idade dos idosos, a maioria tem entre 60 e 69 anos (92 pessoas - 52\%), seguido das pessoas com idade entre 70 e 79 anos (56 pessoas - 31.6\%). Dos sujeitos que participaram da pesquisa, 13,5\% têm idade entre 50 e 59 anos (24 pessoas) e 2,9\% têm idade entre 80 e 89 anos (5 pessoas).

Quadro 2: Idade

\begin{tabular}{l|c|c|c|c|c|c|c|c|c|c|c|c|c|c}
\hline Idade & UEPG & UCS & FURB & UFES & UNIFAL & UERJ & UCDB & $\begin{array}{c}\text { PUC- } \\
\text { GO }\end{array}$ & UFPE & UESC & UFS & UEA & Total & $\%$ \\
\hline 50 anos & & 5 & & 1 & 4 & & 5 & 2 & & 2 & & 5 & 24 & $13.5 \%$ \\
\hline 60 anos & 11 & 8 & 6 & 5 & 8 & 4 & 8 & 10 & 10 & 6 & 8 & 8 & 92 & $52 \%$ \\
\hline 70 anos & 3 & 2 & 8 & 8 & 3 & 9 & 2 & 3 & 5 & 4 & 7 & 2 & 56 & $31.6 \%$ \\
\hline 80 anos & 1 & & 1 & 1 & & 2 & & & & & & & 5 & $2.9 \%$ \\
\hline
\end{tabular}

Fonte: Elaboração das autoras com base nos dados coletados.

O sexo que predomina é o feminino com 157 alunas (88,7 \%). Há 20 homens, o que corresponde 11,3\%. Este dado confirma o processo de feminilização da velhice que é abordado por muitos estudiosos como Oliveira (1999).
O estado civil que predomina é o de casado, com 67 pessoas (37,8\%), seguido de viúvo com 51 pessoas (28,8\%), separado 30 pessoas (16,9\% ) e solteiros 25 pessoas $(14,1 \%)$.

Identificando o grau de escolaridade dos sujeitos investigados pode-se estabelecer uma diversidade neste aspecto. 
Quadro 3: Escolaridade

\begin{tabular}{|c|c|c|c|c|c|c|c|c|c|c|c|c|c|c|}
\hline Escolaridade & UEPG & UCS & FURB & UFES & UNIFAL & UERJ & UCDB & \begin{tabular}{|c|} 
PUC- \\
GO
\end{tabular} & UFPE & UESC & UFS & UEA & Total & $\%$ \\
\hline $\begin{array}{l}1^{\circ} \text { Grau } \\
\text { Completo }\end{array}$ & 4 & 2 & 2 & 1 & 1 & 3 & 1 & & 3 & & & 2 & 18 & $10.1 \%$ \\
\hline $\begin{array}{l}1^{\circ} \mathrm{Grau} \\
\text { Incompleto }\end{array}$ & 2 & 1 & 2 & & 3 & & 2 & & & 2 & & 1 & 14 & $7.9 \%$ \\
\hline $\begin{array}{l}2^{\circ} \text { Grau } \\
\text { Completo }\end{array}$ & 4 & 4 & 8 & 7 & 4 & 5 & 5 & 6 & 7 & 4 & 11 & 6 & 71 & $40.1 \%$ \\
\hline $\begin{array}{l}2^{\circ} \mathrm{Grau} \\
\text { Incompleto }\end{array}$ & 1 & 1 & 1 & 2 & 1 & & 2 & 2 & 1 & & & 3 & 15 & $8.5 \%$ \\
\hline $\begin{array}{l}\text { Ensino } \\
\text { Superior }\end{array}$ & 2 & 6 & 1 & 3 & 3 & 7 & 4 & 3 & 4 & 3 & 3 & 2 & 41 & $21.1 \%$ \\
\hline $\begin{array}{l}\text { Pós- } \\
\text { Graduação }\end{array}$ & 2 & 1 & 1 & 2 & 2 & & 1 & 4 & & 3 & 1 & 1 & 18 & $10.1 \%$ \\
\hline
\end{tabular}

Fonte: Elaboração das autoras com base nos dados coletados.

Pode-se observar, a partir do quadro sobre a escolaridade, que a maioria dos alunos das instituições investigadas tem o $2^{\circ}$ Grau Completo (Ensino Médio), dado representado por 71 pessoas, ou seja, 40,1\%. Na sequência, destaca-se a escolarização em Ensino Superior, por 41 pessoas (21,1\%). Entretanto, ainda uma quantidade significativa de idosos não tem a Educação Básica completa (18 pessoas com Ensino Fundamental completo, 14 pessoas com Ensino Fundamental incompleto e 15 pessoas com Ensino Médio incompleto: 47 pessoas, ou seja, 26,5\%).
A renda mensal familiar identificada refere-se à predominância de 43 pessoas, com renda familiar de mais de 5 salários mínimos (24,3\%). Todavia, existe um equilíbrio nos dados, pois 30 pessoas têm renda mensal familiar de até 1 salário mínimo (16,9\%), 21 pessoas com renda de 1 a 2 salários mínimos (11,9\%), 29 pessoas com renda de 2 a 3 salários mínimos (16,4\%), 34 pessoas com renda familiar de 3 a 4 salários mínimos (19,2\%) e 20 pessoas com renda familiar de 4 a 5 salários mínimos (11,3\%).

Quadro 4 - Renda mensal familiar

\begin{tabular}{l|c|c|c|c|c|c|c|c|c|c|c|c|c|c}
\hline $\begin{array}{l}\text { Salários } \\
\text { mínimos }\end{array}$ & UEPG & UCS & FURB & UFES & UNIFAL & UERJ & UCDB & $\begin{array}{c}\text { PUC- } \\
\text { GO }\end{array}$ & UFPE & UESC & UFS & UEA & Total & $\%$ \\
\hline Ate 1 & 3 & & & 1 & 3 & 2 & 1 & 2 & 6 & 3 & 4 & 5 & 30 & $16.9 \%$ \\
\hline De 1 até 2 & 2 & 3 & & 2 & 4 & 1 & 2 & 3 & 1 & & 1 & 2 & 21 & $11.9 \%$ \\
\hline De 2 até 3 & 1 & 2 & 4 & 4 & 2 & 2 & 1 & 1 & 4 & 3 & 1 & 4 & 29 & $16.4 \%$ \\
\hline De 3 a 4 & 3 & 5 & 4 & 3 & 2 & 1 & 3 & 3 & 1 & 2 & 5 & 2 & 34 & $19.2 \%$ \\
\hline De 4 a 5 & 1 & 2 & 2 & 2 & 3 & 1 & 3 & 1 & 1 & 2 & 2 & & 20 & $11.3 \%$ \\
\hline Mais de 5 & 5 & 3 & 5 & 3 & 1 & 8 & 5 & 5 & 2 & 2 & 2 & 2 & 43 & $24.3 \%$ \\
\hline
\end{tabular}

Fonte: Elaboração das autoras com base nos dados coletados.

Um aspecto interessante é o predomínio de que 150 idosos moram em casa própria, representando $84,7 \%$, seguido de casa alugada referenciada por17 idosos (9,6\%), moradia em casa cedida foi apontada por 8idosos (4,5\%) e
2 idosos apontaram que não possuem moradia fixa (1,1\%). A questão familiar também reflete muito no comportamento e na qualidade devida dos idosos, sendo importante considerar com quem moram. 
Quadro 5: Com quem mora

\begin{tabular}{l|c|c|c|c|c|c|c|c|c|c|c|c|c|c}
\hline & UEPG & UCS & FURB & UFES & UNIFAL & UERJ & UCDB & $\begin{array}{c}\text { PUC- } \\
\text { GO }\end{array}$ & UFPE & UESC & UFS & UEA & Total & $\%$ \\
\hline Companheiro & 7 & 10 & 9 & 4 & 6 & 1 & 9 & 5 & 7 & 4 & 3 & 2 & 67 & $37.5 \%$ \\
\hline Filho & 5 & 5 & 1 & 4 & 4 & 6 & 4 & 1 & 2 & 3 & 7 & 7 & 49 & $27.6 \%$ \\
\hline $\begin{array}{l}\text { Outro } \\
\text { parente }\end{array}$ & & & & 2 & & 1 & & 5 & 2 & 1 & & & 11 & $6.2 \%$ \\
\hline Sozinho & 3 & & 5 & 5 & 5 & 7 & 2 & 4 & 4 & 4 & 5 & 6 & 50 & $28.2 \%$ \\
\hline
\end{tabular}

Fonte: Elaboração das autoras com base nos dados coletados.

A maioria dos idosos - 67 pessoas (37,5\%) - vive com companheiro (esposo/ esposa). Outras 50 pessoas $(28,2 \%)$ vivem sozinhas. Há ainda 49 idosos que vivem com seus filhos $(27,6 \%)$.
Considerando o número de filhos, destacam-se 55 idosos com 2 filhos (31\%), seguido de 44 idosos com 3 filhos (24,8\%) e 36 idosos com 4 filhos ou mais (20,3\%). Uma parcela significativa de idosos (26 - 14,7\%) não possuem filhos.

Quadro 6: Possui quantos filhos

\begin{tabular}{l|c|c|c|c|c|c|c|c|c|c|c|c|c|c}
\hline Filhos & UEPG & UCS & FURB & UFES & UNIFAL & UERJ & UCDB & $\begin{array}{c}\text { PUC- } \\
\text { GO }\end{array}$ & UFPE & UESC & UFS & UEA & Total & $\%$ \\
\hline Não tem & & 3 & 1 & 3 & 1 & 3 & 2 & 6 & 3 & 2 & 2 & & 26 & $14.7 \%$ \\
\hline 1 & & 3 & & 1 & 2 & 3 & & & 1 & 1 & & 5 & 16 & $9 \%$ \\
\hline 2 & 2 & 6 & 5 & 4 & 5 & 7 & 7 & 3 & 3 & 3 & 5 & 5 & 55 & $31 \%$ \\
\hline 3 & 3 & 1 & 8 & 3 & 3 & 2 & 3 & 4 & 6 & 6 & 3 & 2 & 44 & $24.8 \%$ \\
\hline 4 ou mais & 10 & 2 & 1 & 4 & 4 & & 3 & 2 & 2 & & 5 & 3 & 36 & $20.3 \%$ \\
\hline
\end{tabular}

Fonte: Elaboração das autoras com base nos dados coletados.

Ao considerar o ingresso dos idosos nas atividades extensionistas (UATI), houve o questionamento sobre a quantidade de tempo que frequentam o projeto/programa.

Quadro 7: Tempo que frequenta a UATI

\begin{tabular}{l|c|c|c|c|c|c|c|c|c|c|c|c|c|c}
\hline & UEPG & UCS & FURB & UFES & UNIFAL & UERJ & UCDB & $\begin{array}{c}\text { PUC- } \\
\text { GO }\end{array}$ & UFPE & UESC & UFS & UEA & Total & $\%$ \\
\hline $\begin{array}{l}\text { Menos de } 1 \\
\text { ano }\end{array}$ & 1 & & 1 & 4 & & 1 & 4 & 8 & 8 & 3 & 1 & 4 & 35 & $19.8 \%$ \\
\hline 1 a 3 anos & 8 & 7 & 6 & 3 & 2 & 4 & 11 & 6 & 2 & 5 & 10 & 2 & 66 & $37.3 \%$ \\
\hline 4 a 6 anos & 1 & 5 & & 6 & 6 & 1 & & & 3 & 2 & 4 & 8 & 36 & $20.3 \%$ \\
\hline 7 a 9 anos & 4 & 1 & 3 & & 4 & 1 & & 1 & & & & 1 & 15 & $8.5 \%$ \\
\hline $\begin{array}{l}10 \text { anos ou } \\
\text { mais }\end{array}$ & 1 & 2 & 5 & 2 & 3 & 8 & & & 2 & 2 & & & 25 & $14.1 \%$ \\
\hline
\end{tabular}

Fonte: Elaboração das autoras.

No quadro 7, pode-se observar que há 37,3\% dos sujeitos com frequência entre 1 e 3 anos, seguidos de 36 com frequência entre 4 e 6 anos (20,3\%). Outros 35 estão nas UATIs há menos de 1 ano (19,8\%). Há 25 idosos que estão nos projetos/programas há 10 anos ou 
mais (14,1\%). Entre 7 e 9 anos de frequência nas UATIs há 15 idosos (8,5\%).

Considerando os motivos que levaram o idoso a frequentarem a UATI, pode-se perceber que predomina a melhoria da qualidade de vida (129 idosos - 30,3\%), seguida de vontade de aprender (111 idosos - 26,1\%) e conhecer novas pessoas (90 idosos - 21,1\%).

Outros motivos também foram indicados, entre os quais: porque queriam uma nova ocupação (51 idosos - 12 \%), por indicação de amigos ou parentes (43 idosos - 10,1\%) e por imposição de familiares ( 1 idoso - 0,25 \%).

Quando questionados sobre o que mais gostam na UATI, as respostas ficaram equilibradas: aulas (117 pessoas - 23,7\%), possibilidade de aprender (110 pessoas - 22,2\%), professores (102 pessoas - 20,6\%) e colegas (97 pessoas - 19,6\%). Com menos incidência: atividades recreativas/festas (68 pessoas - 13,7\%).

Quadro 8 - O que mais gosta na UATI

\begin{tabular}{l|c|c|c|c|c|c|c|c|c|c|c|c|c|c}
\hline & UEPG & UCS & FURB & UFES & UNIFAL & UERJ & UCDB & $\begin{array}{c}\text { PUC- } \\
\text { GO }\end{array}$ & UFPE & UESC & UFS & UEA & Total & $\%$ \\
\hline Aulas & 12 & 10 & 7 & 12 & 11 & 7 & 12 & 14 & 11 & 8 & 4 & 9 & 117 & $23.7 \%$ \\
\hline Colegas & 13 & 9 & 4 & 11 & 5 & 9 & 11 & 8 & 8 & 7 & 4 & 8 & 97 & $19.6 \%$ \\
\hline $\begin{array}{l}\text { Professores } \\
\text { Atividades } \\
\begin{array}{l}\text { recreativas/ } \\
\text { festas }\end{array}\end{array}$ & 11 & 11 & 5 & 11 & 6 & 8 & 12 & 9 & 9 & 10 & 3 & 7 & 102 & $20.6 \%$ \\
\hline $\begin{array}{l}\text { Possibilidade } \\
\text { de aprender }\end{array}$ & 6 & 10 & 13 & 11 & 9 & 7 & 11 & 11 & 5 & 9 & 11 & 7 & 110 & $22.2 \%$ \\
\hline
\end{tabular}

Fonte: Elaboração das autoras com base nos dados coletados.

Outro aspecto muito interessante refere-se às mudanças na própria vida que os idosos registraram depois que passaram a frequentar a UATI, que estão indicadas no quadro abaixo (nesta questão, os sujeitos puderam eleger mais de uma alternativa como resposta).

Quadro 9 - Mudanças

\begin{tabular}{l|c|c|c|c|c|c|c|c|c|c|c|c|c|c}
\hline Mudanças & UEPG & UCS & FURB & UFES & UNIFAL & UERJ & UCDB & $\begin{array}{c}\text { GUC- } \\
\text { GO }\end{array}$ & UFPE & UESC & UFS & UEA & Total & $\%$ \\
\hline $\begin{array}{l}\text { Conheci novas } \\
\text { pessoas. }\end{array}$ & 13 & 14 & 12 & 12 & 7 & 13 & 11 & 13 & 11 & 10 & 11 & 8 & 135 & $28.2 \%$ \\
$\begin{array}{l}\text { Descobri que } \\
\text { tenho capacidade } \\
\text { de aprender } \\
\text { coisas novas. }\end{array}$ & 12 & 13 & 9 & 10 & 11 & 9 & 13 & 8 & 13 & 5 & 10 & 7 & 120 & $25.1 \%$ \\
$\begin{array}{l}\text { Estou realizando } \\
\text { atividades } \\
\text { diversificadas. }\end{array}$ & 8 & 9 & 7 & 12 & 7 & 8 & 9 & 8 & 6 & 8 & 10 & 3 & 95 & $19.9 \%$ \\
$\begin{array}{l}\text { Sinto-me mais } \\
\text { realizado. }\end{array}$ & 10 & 14 & 7 & 9 & 5 & 10 & 10 & 8 & 10 & 9 & 9 & 5 & 106 & $22.2 \%$ \\
\hline $\begin{array}{l}\text { Superei o } \\
\text { sentimento de } \\
\text { solidão. }\end{array}$ & 5 & 3 & 6 & 4 & 2 & 4 & 5 & 4 & 5 & 4 & 7 & 4 & 53 & $11 \%$ \\
\hline $\begin{array}{l}\text { Sinto que sou } \\
\text { útil. }\end{array}$ & 8 & 9 & 1 & 8 & 5 & 8 & 8 & 4 & 10 & 6 & 8 & 4 & 79 & $16.5 \%$ \\
\hline
\end{tabular}

Fonte: Elaboração das autoras com base nos dados coletados. 
Para 135 pessoas (28,2\%), a principal mudança refere-se a conhecer novas pessoas. Outras 120 pessoas (25,1\%) apontaram que descobriram sua capacidade de aprender. Para 106 pessoas (22,2\%), a mudança refere-se a sentir-se mais realizado. Há também a indicação de realização de atividades diversificadas, por 95 pessoas (19,9\%). Há 79 pessoas que afirmam que se sentem úteis (16,5\%) e outras 53 apontam que superaram a solidão (11\%).

A partir dos dados apresentados, observa-se que o idoso que frequenta as UATIs brasileiras indica, pela sua inserção nestas ações extensionistas, alterações importantes em sua vida, aceita a ação proposta e tem um tempo de frequência significativo (alguns programas são mais recentes, o que representa uma grande quantidade de alunos frequentando-os entre 1 e 3 anos).

Ao se considerar o perfil dos alunos destas ações, é possível planejar de forma mais adequada as atividades a serem desenvolvidas, preocupando-se em atender às demandas destas pessoas, embora já respondam positivamente à sua inserção nas UATIs.

Também cabe aos coordenadores, professores, alunos e comunidades universitárias a divulgação e a valorização das ações realizadas pelas UATIs, para que este tipo de ação extensionista seja conhecido em diferentes âmbitos da sociedade e reconhecido pelos benefícios que trazem para a população idosa que o frequenta. Além disso, torna-se fundamental o incentivo (público) para que outras instituições também estendam suas ações para o idoso, com a criação de novas universidades abertas para a terceira idade no Brasil.

\section{Considerações finais}

As ações extensionistas oferecidas para a terceira idade devem assumir uma postura de amplitude, permitindo o desenvolvimento do idoso, a fim de possibilitar a sua inclusão e a participação cidadã. Deve ser privilegiada a aprendizagem, por um lado se confrontando com o rompimento do preconceito de que o idoso tem menor capacidade de aprendizagem e, por outro lado, fazendo emergir a aprendizagem com sabor de conquista, de vitória, elevando a autoimagem do idoso, além de aguçar-lhe o sentido de utilidade, aprimorando a capacidade crítica, a liberdade de expressão e a participação desse segmento da população.

As universidades, assumindo também a tarefa de desenvolvimento cultural do segmento idoso, ampliam o seu compromisso social, integrando os que se encontram à margem do processo de desenvolvimento e, por conseguinte, levando-os a usufruir os bens advindos da proposta.

Estas ações de extensão universitária possibilitam também aos idosos ascenderem em três grandes áreas de empoderamento: o poder como maior confiança na capacidade pessoal para levar adiante algumas formas de ação; o poder como aumento das relações efetivas que as pessoas desprovidas de poder podem estabelecer com outras organizações; o poder como resultado da ampliação do acesso dos recursos econômicos.

A extensão voltada à terceira idade, nas universidades, apresenta um propósito bem definido: o empoderamento, a inclusão e a melhoria da qualidade de vida. Assim, as ações extensionistas buscam ressignificar os sentidos dados à própria existência, bem como ampliar as relações sociais dos sujeitos, seja no grupo em que estão inseridos seja em outros grupos sociais. Estas ações também almejam produzir conhecimentos que ampliem as possibilidades de atuação e participação, subsidiando a análise, a avaliação e a implementação de políticas públicas pertinentes. 


\section{Referências}

ALVES, C. N. O coordenador pedagógico como agente para a inclusão. In: SANTOS, M. P.; PAULINO, M. M. (Orgs.). Inclusão em educação: culturas, políticas e práticas. São Paulo: Cortez, 2008.

BRASIL. Constituição da República Federativa do Brasil: promulgada em 5 de outubro de 1988. São Paulo: Saraiva, 2005.

Lei n. 10741 de 1 de outubro de 2003. Dispõe sobre o Estatuto do Idoso. Brasília, 2003.

. Lei n. 9394, de 20 de dezembro de 1996. Estabelece as diretrizes e bases para a educação nacional. Diário Oficial da União, Brasília, 23 dez. 1996. Disponível em: < http://portal.mec.gov.br/setec/arquivos/pdf/ LF9394_96.pdf>. Acesso em: 15 mai. 2016.

CASTEL, R. As metamorfoses da questão social: uma crônica do salário. Petrópolis: Vozes, 1998.

CASTRO, L. M.C.Auniversidade, a extensão universitária e a produção de conhecimentos emancipadores. In: REUNIÃO ANUAL DA ANPED, 27., 2004, Caxambu. Anais eletrônicos... Caxambu: ANPED, 2004. Disponível em: < http://www.anped.org.br/ sites/default/files/t1111.pdf $>$. Acesso em: 15 mai. 2016.

COSTA, A. C. G. da Fundamentos teóricos e metodológicos da pedagogia social no Brasil. In: CONGRESSO INTERNACIONAL DE PEDAGOGIA SOCIAL, 1., 2006, São Paulo. Anais eletrônicos... São Paulo: USP, 2006. Disponível em: < http://www.proceedings. scielo.br/scielo.php?pid=MSC0000000092 006000100007\&script=sci_arttext $>$ Acesso em: 18 mai. 2014.
FALEIROS, V. P. Cidadania e direitos da pessoa idosa. Revista SER Social. Brasília, v. 20, p. 35-61, jan./jun. 2007.

Inclusão social e cidadania. In: INTERNATIONAL CONFERENCE ON SOCIAL WELFARE, 32., 2006, Brasília. Anais eletrônicos... Brasília: ICSW, 2006. Disponível em: < http://www.icsw.org/ images/docs/Events/2006_Brazil/17_07_ PDF/vicente_faleiros.pdf $>$. Acesso em: 15 mai. 2016.

FÓRUM DE PRÓ-REITORES DE EXTENSÃO DAS UNIVERSIDADES PÚBLICAS BRASILEIRAS - FORPROEX. Extensão universitária: organização e sistematização. Belo Horizonte: COOPMED, 2007. Disponível em: <www.renex.org.br>. Acesso em: 10 abr. 2014.

. Plano Nacional de Extensão. Rio de Janeiro: UERJ/MEC/FORPROEX, 1999. Disponível em: <www.renex.org.br>. Acesso em: 10 abr. 2014.

Extensão universitária: diretrizes conceituais e políticas. Brasília: MEC/ FORPROEX, 1987. Disponível em: <www. renex.org.br>. Acesso em 12 set. 2012.

FREIRE, S. Um olhar sobre a inclusão. Revista da Educação, Lisboa, v. 16, n. 1, p. 5-20, 2008.

GOHN, M. G. Educação não-formal, participação da sociedade civil e estruturas colegiadas nas escolas. Ensaio: Avaliação e Políticas Públicas em Educação, Rio de Janeiro, v. 14, n. 50, p.27-38, mar.2006.

GUIMARÃES, R. G. M.; FERREIRA, M. C.; VILLAÇA, F. M. O debate necessário: a importância da extensão universitário para a formação médica. Cadernos ABEM, Rio de Janeiro, v. 4, p. 69-78, out. 2008.

LUTZ, A.; TEIXEIRA, A. M. R. Escolarização de jovens e adultos: em defesa 
de práticas culturais. In: FARENZENA, R. C. (Orgs.). Educação de jovens e adultos. Passo Fundo: UPF, 2004. p. 134-154.

NOGUEIRA, M. D. P. Extensão universitária no Brasil: uma revisão conceitual. In. FARIA, D. S. (Org.). Construção conceitual da extensão na America Latina. Brasília: UNB, 2001.

OLIVEIRA, R. C. S. Terceira idade: do repensar dos limites aos sonhos possíveis. Campinas: Paulinas, 1999.

SANTOS, M. P.; PAULINO, M. M. (Orgs.). Inclusão em educação: culturas, políticas e práticas. São Paulo: Cortez, 2008.

SAVIANI, D. Ensino público e algumas falas sobre universidade. São Paulo: Cortez, 1990.

SERRANO, R. M. S. M. Conceitos de extensão universitária: um diálogo com Paulo Freire. João Pessoa: UFPB, s/d Disponível em: <http://www.prac.ufpb.br/ copac/extelar/atividades/discussao/artigos/ conceitos_de_extensao_universitaria.pdf $>$. Acesso em: 18 mai. 2014.

TORRES, M. M.; SÁ, M. A. A. S. Inclusão social de idosos: um longo caminho a percorrer. Revista Ciências Humanas, Taubaté, v. 1, n. 2, p.1-10, 2008. 